\title{
Mobile Application Development for Technology Enhanced Learning: An Applied Study on the Students of the College of Mass Communication at Ajman University
}

\author{
https://doi.org/10.3991/ijet.v15i08.12551 \\ Nidal Al Said \\ Ajman University, Ajman, UAE \\ n.alsaideajman.ac.ae
}

\begin{abstract}
Educational applications play an important role in modern education. Based on this, the objectives of this study are as follows: analyze a student interview (focus group) that has been conducted among University student of college of Mass Communication at Ajman University; determine the characteristics of educational applications; find out possible advantages and disadvantages of educational applications; formulate, including based on a student interview, criteria for choosing educational applications; divide educational applications into different categories to more fully see the academic possibilities of their use; develop student skills. Based on the objectives, it is decided to divide the study into two parts. The first step is to analyze semistructured interviews that have been conducted with students. In the second part of the study, a list of educational applications is compiled, indicating their educational categories.
\end{abstract}

Keywords-Mobile application development; technologies in education; modern education; distance learning; mass communication; student skills development.

\section{Introduction}

Over the past decade, the use of mobile devices has increased dramatically $[1,2]$. According to a recent study, more than a third of American children under two years old have used mobile devices to access media [3]. More and more young children use various mobile devices for communication, learning and games [4]. Thus, many researchers and teachers are increasingly interested in the possibilities of mobile learning and are exploring ways to effectively use mobile devices for teaching children [5,6]. Due to the simplicity of portability, touch screens, and improvements to user interfaces, researchers expect mobile devices to offer tremendous educational potential, especially for young children in preschools and kindergartens [7].

Mobile technologies (smartphones and tablet computers) can use other technological applications, such as e-books, digital video materials, podcasts, social networks and cloud computing [7]. Studying the educational potential of mobile devices for children is important and increasingly relevant. In 2011, the research team 
Common Sense Media conducted a study on the use of the media by children from 0 to 8 years old throughout America. Just two years later, they repeated their study and found a sharp increase in the access of young children to mobile devices and their use. Young children often cannot make individual decisions about when and how they will use mobile devices. Thus, parents, teachers and guardians have the primary responsibility for such an increased use and will continue to play a major role in deciding when, where and how content will be viewed on mobile devices by children [8].

Due to the sharp increase in the use of mobile devices, many have wondered how these devices will affect learning. Currently, five mobile learning opportunities are being identified:

- Encouraging learning anywhere, anytime

- Covering children from low-income families

- Improving social interactions in the 21 st century

- Fitting the learning environment

- Providing personalized learning experience [9]

These capabilities are associated with the continuous (transition from device to device and/or context to context) and ubiquitous (increasingly open access anywhere at any time) nature of mobile devices. Mobile devices are increasingly blurring the line between learning activities at school and at home. Thus, a child can learn at any time of the day. For example, children can use the app to learn the alphabet when traveling with their parents in a car, play development games while sitting in a shopping basket, or access facts about the local environment while walking in a local park [10].

While these opportunities are exciting and encouraging, it is also important to consider the challenges associated with integrating mobile learning into children's daily lives [11]. Three categories of mobile learning problems can be defined: social, theoretical, and technological. Social problems with mobile learning for young children arise mainly due to concerns about the time spent in front of the screen. This can hinder the development of self-regulation, social skills, practical skills, communication and interpersonal skills, teamwork and sensorimotor skills [12 13]. The theoretical problem for researchers and developers in the field of mobile learning is as follows. Namely, there is no unique structure or general theory that would guide the development of effective mobile learning environments. In addition, there are some technical problems associated with the use of mobile devices for educational purposes. Designers should create applications that run on a relatively small screen and are user-friendly for both novice digital users (usually children) and digital immigrants. In the case of children, adults most often should be near to eliminate any technical difficulties during learning activities [14].

Today, it is common to perform a large number of tasks using mobile technologies. For example, answering e-mail, reading a book, writing text or communicating with other people through social networks. However, there are still serious problems associated with the integration of such technology in e-learning practices. The term "e-learning" coexists with the concepts of web education, distance learning, online 
learning, etc., which are used equally. One of the biggest challenges of mobile learning is ensuring that the tasks match the capabilities of the devices used, especially when considering informal student learning processes [15]. There is no clear separation of formal and non-formal learning. Both forms can be considered complementary, since they coexist in practice, in particular for distance students. Non-formal learning occurs naturally without direct efforts and does not have formal documentation, while formal learning includes organized educational institutions and documentation. Informal learning processes are studied in order to improve formal ones and better correspond to different educational situations of students [16].

There are two approaches to the research, content, and design of language learning through mobile learning. While the latter is related to the constant transition to research, which is related to design. Research in the field of mobile learning that was conducted between 2003 and 2010, was largely focused on the development of mobile learning systems. In a recent literature review with a special emphasis on mobile learning, it was found that many widely cited studies focus on the development of mobile language learning systems and the experimental evaluation of their effectiveness.

The rapid development of mobile technology over the past two decades has created new design contexts and practices. The effective integration of mobile technology into educational practices depends on factors related to people (students and teachers), design (content and technology) and institutions (policies and strategies). This makes their development a difficult task. Although there are many examples of new designs, there is little research on the rationale for developing education procedures [17]. Distinctive features of mobile technologies are flexibility and connectivity. Although technology does not determine development, these characteristics become vital components that must be considered when developing new learning conditions. Effective use to a large extent depends on the specific possibilities of technologies that should fit into the target educational environment, as well as in the contexts of use and educational methods of students [18].

The context of student use is the crucial difference between mobile and non-mobile technologies. Although non-mobile technologies are installed in environments designed for certain types of activities, mobile technologies can be used in almost any environment. Such types of activities for non-mobile technologies include, for example, work-related or educational tasks that involve longer sessions. There are also various types of tasks that technology supports. The learning objectives (formulated by instructors in higher education) today are often associated with the mandatory use of a learning management system. Where the choice of such technological learning objectives depends on the preferences and decisions of teachers, and not on students. These systems are primarily intended for use on desktop computers and laptops and are functionally limited in their ability to access via mobile devices. Students in their daily lives use mobile technologies for independent tasks of various kinds [19]. Thus, it can be concluded that mobile technologies can be widely used in education. In this regard, the objectives of this study are formed: 
- Analyze an interview that has been conducted among university students of the college of mass communication ("Graphic Design", "Public relations and advertisement", and "Radio and TV" majors) at Ajman university to highlight the characteristics of educational applications, as well as their possible advantages and disadvantages;

- Formulate, incl. based on the interview, criteria for selecting educational applications;

- Divide educational applications into various categories to more fully see the academic possibilities of their use.

- Develop a mobile application to develop student skills in learning

\section{$2 \quad$ Method}

\subsection{Research design}

Based on the goals, it was decided to divide the study into two parts. The first part included semi-structured interviews with students, in which they were invited to share their opinions on what educational applications should be (see Appendix). Conducting such an interview specifically among students plays an important role since they are the direct recipients of such products. In the second part of the study, a list of education applications is compiled, indicating educational categories. As well as selection criteria for education applications that also will help them to develop their skills.

\subsection{Participants}

Students from 3 majors ("Graphic Design", "Public relations and advertisement", and "Radio and TV") of college of mass communication at Ajman university took part in an interview. In total, 100 students aged 19 to 21 years were interviewed. The number of men and women was approximately equal. Language used for the interview is Arabic. Students from different Arabic countries took part in the interview (UAE, Jordan, Sudan, Egypt, Syria, Lebanon etc.) Also 2 specialists and representative of the university's IT department; 6 instructors form college of mass communication and 4 instructors from college of "engineering and information technology" at Ajman University were interviewed. 2 interviews were conducted, one concerning the importance of smart phones and their applications and the other the concept of human - computer interaction and the skills they want to gain while using the mobile applications.

\subsection{The participant's selection criterion}

The decision to conduct an interview specifically among students of higher educational institutions, and not schools, is due to the fact that at this stage they are more well-formed individuals who are ready to evaluate any subjects or phenomena. 
In addition, students are more focused on obtaining a specific result in their studies, which may also affect the completeness of their opinion on the qualities of educational applications.

\subsection{Research instrument}

During the interview, the method of semi-structured interviews was used. This research method is qualitative, that is, it allows one to collect not only statistical data. The use of semi-structured interviews helped to more fully learn the opinion of students. Since in this case they are not limited to answer options and have the opportunity to express their opinion.

Respondents were asked to answer two questions:

- "What, in your opinion, should be an education application?"

- "What, in your opinion, are the pros and cons of education applications?"

- "What skills you want to develop?"

They were told that when answering, they can talk about any characteristics of such applications, whether design or functional component.

\subsection{Research issues and restrictions}

Only representatives of one age group took part in the interview, which makes it impossible to judge the situation, for example, among school students or working citizens.

\subsection{Data analysis}

Semi-structured interviews relate to a qualitative research methodology. During the interview, all of the students' answers were recorded and analyzed, thanks to which the most common wordings were highlighted among them. Further, the received responses were structured. For those response categories where percentage allocation was required, the STATISTICA system was used. This software, developed on Microsoft Windows basis, allows one to visualize data during statistical analysis.

\section{$3 \quad$ Results}

In summing up the results, it was decided to combine similar answers into general categories. It is also worth noting that when presenting the results, all categories are arranged in random order. 


\subsection{Functionality}

This category includes all answers related to the technical content of the applications. Many respondents noted that one of the most important qualities of an application for them is a variety of functions. For example, an application for learning a language should have lexical, grammatical, and other aspects. According to the respondents, they are more likely to opt for installing a single application with various functions rather than several separate ones, but with the same functionality.

\subsection{Intuitiveness}

Respondents considered intuitiveness in use as another important criterion for an education application. They noted that the success of working with the application depends, inter alia, on how clear and convenient the interface is. According to many respondents, it should be simple and understandable. This will allow one to more effectively acquire knowledge since in a convenient application there is no need to spend time and resources on understanding its operating principle.

\subsection{Progress tracking}

The ability to track progress was also important for many respondents. They found it especially useful for those applications that students use for self-education. A progress bar or any other indicator will allow one to see how efficiently the work is being done. In addition, such a function will allow one to track in which aspects or topics difficulties have arisen. Thanks to this, students can understand which topics they should focus more on.

\subsection{Relationship with university studies}

This item was not very popular; however, a sufficient number of respondents expressed the view that it is necessary to develop an application whose content will be in line with the curriculum. In their opinion, such applications will help diversify the educational process, as well as consolidate the knowledge already gained. For example, a proposal was made to create an application in which, after listening to a lecture, tasks related to it will be opened.

\subsection{User-friendly interface}

The visual component, according to students, also plays a rather important role. According to them, websites or applications that have a user-friendly interface increase the desire to learn, as well as spend more time on it. The mandatory attributes of a good interface were named:

- Colors (not too bright, not too faded) 
- The ability to turn on the night mode function (changing the color and brightness of the screen depending on lighting so that one's eyes do not get tired)

- The ability to adjust the font, etc. Many students found that the availability of images and audio files is necessary.

\subsection{Feedback}

This item, rather, is directly related to the creation of applications for each university. In this case, the respondents considered feedback necessary with the teacher, which can be carried out directly in the application, and not in person. Suggestions were also made to create a forum inside the education application, where anyone can ask questions to other users. However, such an initiative can have negative consequences, as the respondents will also be students and may answer incorrectly.

\subsection{Multilingualism}

Extending the language coverage of educational applications plays an important role in disseminating their use. Some respondents noted that they do not always have the opportunity to use an application, since it is not translated into their native language, and the knowledge of other languages does not allow them to complete the work. They noted that it is necessary to use in applications not only English, Arabic and popular European languages but also those that may be less common.

The pros and cons are highlighted based on the features of education using applications. It is necessary to talk about them, since when deciding to apply a similar method in practice, everyone should be able to consider the phenomenon from different angles.

The advantages are as follows:

Interactivity: Using the application on a mobile phone allows one to make the learning process more interactive. Through various means such as animation, color changes, tooltips, etc., the study of a topic becomes more interesting and attractive.

Mobility: Unlike traditional teaching materials, educational applications can be used absolutely everywhere, since almost every modern person has a smartphone with the ability to install them. Especially if applications do not require an Internet connection. This allows one to make the learning process more mobile and learn, for example, while standing in a traffic jam or waiting in line for a doctor's appointment.

\subsection{Variety of approaches}

Often, educational applications include various components: pictures (visual), text, various sounds and audio recordings. This allows making the learning process more diverse. In addition, it will allow people with different types of perception to better perceive information. For example, someone better understands by ear, while someone needs text.

Among the minuses there are: 
Access problems: Despite the fact that most modern people have smartphones with the ability to install applications, there are a considerable number of those whose technology does not allow this. Thus, some students may be deprived of the opportunity to use educational applications, which puts them in an unequal position with those who have this opportunity.

Health: As it is known, the abuse of gadgets can adversely affect the state of health, no matter what they are used for, for games or for educational purposes. The use of educational applications will inevitably increase the amount of screen time, which can have a negative impact on the health of students.

Learning benefits: App-based learning may not always be effective enough. Especially when it comes to young children, as they often pay more attention to the interactive component, which can adversely affect the learning.

A list of education applications was compiled, in which their didactic opportunities stood out (see Table 1). The purpose of the study is to show how diverse and applicable education applications can be.

Table 1. Didactic features of mobile applications

\begin{tabular}{|c|c|c|}
\hline Type of application & Didactic features & Application examples \\
\hline Communicative & $\begin{array}{l}\text { Organization of autonomous education. } \\
\text { Organization of project activities. } \\
\text { The implementation of feedback. } \\
\text { Self-assessment. } \\
\text { Modernization and optimization of control forms. }\end{array}$ & $\begin{array}{l}\text {-Email. } \\
\text {-Facebook, } \\
\text {-Interview and Feedback } \\
\text { Systems: } \\
\text { Poll everywhere, SRS etc. } \\
\text { - Instant messengers. }\end{array}$ \\
\hline Referential & $\begin{array}{l}\text { Access to meta information. } \\
\text { Creation of mobile exercises for development. } \\
\text { Organization of project activities. } \\
\text { Creation of problem tasks. }\end{array}$ & $\begin{array}{l}\text {-Reading applications: Kindle, } \\
\text { Stanza } \\
\text {-Electronic dictionaries, } \\
\text { encyclopedias, reference books. }\end{array}$ \\
\hline A joint one & $\begin{array}{l}\text { Exchange of ideas, resources, materials. } \\
\text { Organization of project activities. } \\
\text { Creation of problem tasks. }\end{array}$ & $\begin{array}{l}\text { Joint documents: Google Doc } \\
\text {-Mental maps } \\
\text {-Cloud storage }\end{array}$ \\
\hline Documentary & $\begin{array}{l}\text { Organization of autonomous education. } \\
\text { Creation of an electronic portfolio. } \\
\text { Organization of project activities. } \\
\text { Self-assessment. } \\
\text { Group assessment. }\end{array}$ & Cloud storage \\
\hline Multimedia & $\begin{array}{l}\text { Organization of autonomous education. } \\
\text { Creation of mobile exercises and tasks for } \\
\text { development. } \\
\text { Visualization of educational material. } \\
\text { Organization of project activities. }\end{array}$ & $\begin{array}{l}\text {-Podcasts and video podcasts } \\
\text {-Services for creating and } \\
\text { demonstrating interactive } \\
\text { presentations }\end{array}$ \\
\hline Gaming & $\begin{array}{l}\text { Learning during the game. } \\
\text { Implementation and organization of project } \\
\text { activities. } \\
\text { Organization of autonomous education. }\end{array}$ & -Game apps \\
\hline
\end{tabular}

The selection criteria for educational mobile applications are highlighted, based, inter alia, on an interview among students. For convenience, they are divided into categories with a description (see Table 2). 
Table 2. Possible criteria for choosing educational mobile applications

\begin{tabular}{|l|l|}
\hline \multicolumn{1}{|c|}{ Category } & \multicolumn{1}{|c|}{ Detailed characteristics } \\
\hline Technical & - Availability on various operating systems. \\
& - The need to connect to the Internet (offline or online). \\
\hline Financial & - Free or paid. \\
& - the presence of a demo. \\
\hline Psychological and pedagogical & -Audio and/or visual information support; \\
& -Volume of education information; \\
& -The implementation of various forms of interactivity (the presence of \\
a verification system or self-test; the presence of \\
explanations/comments on answers or links to materials); \\
-The availability of test or assignment results for the teacher; \\
-The presence or absence of an authorization system when performing \\
User
\end{tabular}

Thus, mobile applications can be widely used in education, but it is worth considering some features of their use. When deciding to introduce educational applications in everyday life, it is important to make sure that all students have the opportunity (especially technical) to use them in order to maintain equal educational opportunities for all. In addition, it is necessary to apply certain applications, taking into account the needs of a specific group of students in order to apply this method more effectively. The health aspect should also be taken into account and the screen time should be limited for students.

According to the first interview, the majority of respondents agreed that smartphones play an important role in our lives. They noted that the use of smartphones carries not only entertaining and communicative, but also educational, as well as organizational functions. Among the most important characteristics of mobile applications, respondents noted speed, efficiency and ease of use.

Considering the analysis of the second interview, we can conclude that human computer interaction also plays an important role in the modern world. In order to make it comfortable, it is necessary to take into account various aspects, such as design, application support for different platforms, user-friendliness, etc. Mobile application developers should be aware of changing trends, as well as know different programming languages in order to be able to adapt the application to the operating systems of different smartphones.

From the interview of students, specialists and representative of the university, as well as instructors, we can conclude that when developing a mobile application, many factors must be taken into account. Thus, the skills that will be developed while using the application were highlighted. Knowledge of various programming languages will provide an opportunity to expand the number of systems for applications creating. As noted, the appearance of the application plays an important role for the user. That is why must have design skills. This can also include the creation of photo and video materials, the selection of the right colors, etc. Also, one of the design goals of the 
application is to make it easy to use. In addition, students should be involved in at least initial testing. This will allow them to identify possible errors, as well as determine if the application is convenient and useful for other potential users in addition to the student who use the application. Also, knowledge of foreign languages will be a useful skill, as it will allow better control over the content of the application.

\section{Discussions}

The use of educational applications is a rather important topic in modern conditions, which is why various studies on this topic are being conducted. One of these studies took place in 2015 and was aimed at addressing the problems of integrating mobile applications into distance learning. As in this study, the recipients of the said were students. The study was interpretative and focused on the formal and informal practice of language learning by students. Twenty-five distance learning students were interviewed, who studied foreign languages in Sweden. There were fourteen women and eleven men [20].

In addition, in order to understand how the course developers, choose technology, detailed interviews were conducted with two representatives of the university's IT department. A focus group interview was conducted with three instructors teaching the same topic, from the college of mass communication, and one instructor from each major of the college of mass communication (3 instructors). Then another interview was conducted with 4 instructors from the college of Engineering and Information Technology of Ajman University (total 10 instructors). It is usually suggested that a focus group session should have from 6 to 10 participants; however, the "ideal" group size in the focus group method can vary. There is a study showing successful interview practices in focus groups conducted with only two people [21].

Despite the fact that two people are a small number for the focus group, there is a difference compared to the interview; focus groups use discussion and social interaction, while interviews are by definition more focused on questions and answers. One of the instructors had years of experience in technology-based teaching and initially participated in the development of the course (including the development of official course documentation). Another taught the course for the first time on the Internet and was new to such technology practice [22]. Such an aspect of that study is different from the current study, since the authors of the current study conducted the interview only among students who are recipients of educational applications, and not their producers. This document addressed two main research questions: how do students use technology in their educational processes and why do they use some technologies, but not others. An analysis of practical use of technology shows that students use different technologies in different ways and for different purposes in their formal and informal learning environment [23].

In an informal setting, they prefer to use mobile technology because of its accessibility, flexibility, connectivity and interactivity. They often use it in unstructured, special ways that are in line with their daily practice. Thanks to this use, they can often find time to study in the "gaps" between their planned daily activities, 
such as during bus or train rides. However, ongoing discussions about flexibility recognize that there will inevitably be clashes between flexibility and other problems. It is not a case when "more" is "better" [24]. Student practices often rely on previously introduced structures that relate not only to the technologies used, but also to other structures related to their own way of acquaintance, the process of cognition. Such established structures relate to their use of technology in general, which extends to how they use them to learn the language. The structures are also based on their previous learning experiences, thanks to which they developed strategies for learning grammar and vocabulary and for practicing using the new language. Understanding such prescribed structures is important for course developers, as well as for developing software to support student learning practices [25].

Both the nature of the students' interaction with the teaching materials and the strategies they use are volatile and transformative, largely based on their established technology in practice, previous learning experience and their growing knowledge of the new language. The aforementioned structures and practices are based on students' strong preference for self-regulatory individual learning as an effective and often the only accessible form of learning. In contrast, collaborative group activities are considered more difficult to fit into the small- and irregular-time frames available for study. They may be valuable in certain circumstances; for example, group discussions on the Internet are generally seen as helpful in addressing research issues [26].

As for "technology in practice", students use mobile technologies together with their desktop/laptop computers to search for materials not provided by the educational institution that could help in mastering the language:

- Watching TV online

- Read newspapers

- Download various software for vocabulary and structural practice

Using software applications often gives these students the prompt feedback they seek [27]. Thus, the authors can say that this study is somewhat similar to their, since it also examines educational applications in terms of students and their convenience. However, the advantage of the current study is that in it, the interviewed students were able to identify specific pros and cons, as well as characteristics that they would like to see in educational applications and they want to address the skills gained from using such application.

\section{Conclusion}

Educational applications play a rather important role in modern education, as they allow it to provide greater mobility. Based on the goals, it was decided to divide the study into two parts. The first step was to conduct semi-structured interviews with students, in which they were invited to share their opinions on what educational applications should be to develop their skills when use the application. In the second part of the study, a list of education applications was compiled, indicating their education categories. The selection criteria for education applications were also 
highlighted. Students from college of Mass Communication at Ajman University. In total, 100 students aged 19 to 21 years studying in various specialties were interviewed. Also, 2 specialists and representative of the university's IT department; 6 instructors form college of mass communication and 4 instructors from college of "engineering and information technology" at Ajman University were interviewed.

During the study, students named various parameters that they consider important for educational applications. These parameters concerned both the functional component and the design area. Respondents also highlighted the pros and cons of education using applications that were related, inter alia, to health, accessibility and the ability to have equal conditions. Based on students' answers, a list of criteria was compiled in the second part of the study, according to which educational applications should be selected. First of all, when deciding to introduce educational applications in everyday life, it is important to make sure that all students have the opportunity to use them in order to maintain equal educational opportunities for all. In addition, it is necessary to make a choice in favor of those applications that correspond to the needs of a particular group of students. Thus, they will be applied more effectively. The health aspect should also be taken into account and the screen time should be limited for students. Using students and specialists answers we also made a list of the skills that people designing mobile apps must have. Last we addressed the skills the student wants to develop from using such application. Further research can be conducted in schools and colleges, as well as among students in other countries.

\section{References}

[1] Suartama, I.K., Setyosari, P., Sulthoni, S., Ulfa, S. (2019). Development of an Instructional Design Model for Mobile Blended Learning in Higher Education. International Journal of Emerging Technologies in Learning (iJET), 14(16): 4-22. https://doi.org/10.3991/ijet.v14 $\underline{\mathrm{i} 16.10633}$

[2] Razzaq, A., Samiha, Y.T., Anshari, M. (2018). Smartphone Habits and Behaviors in Supporting Students Self-Efficacy. International Journal of Emerging Technologies in Learning, 13(2). https://doi.org/10.3991/ijet.v13i02.7685

[3] Common Sense Media. (2013). Zero to eight: Children's media use in America.

[4] Khlaisang, J., Mingsiritham, K. (2016). Engaging virtual learning environment system to enhance communication and collaboration skills among ASEAN higher education learners. International Journal of Emerging Technologies in Learning (iJET), 11(04): 103-113. https ://doi.org/10.3991/ijet.v11i04.5503

[5] Vu, K., Librenjak, S., Dovedan, Z. (2010). Internet for the youngest: Computer usage and web design for the early school age children. International Journal of Emerging Technologies in Learning (iJET), 5(2010). https://doi.org/10.3991/ijet.v5s2.1215

[6] Prasetya, D.D., Hirashima, T. (2018). Design of Multimedia-based Digital Storybooks for Preschool Education. International Journal Of Emerging Technologies In Learning, 13(2). https://doi.org/10.3991/ijet.v13i02.8188

[7] Judge, S., Floyd, K., Jeffs, T. (2015). Using mobile media devices and apps to promote young children's learning. Young children and families in the information age, educating the young child. New York, NY: Springer, vol. 10, pp. 117-131. https://doi.org/10. $\underline{1007 / 978-94-017-9184-7 \_7}$ 
[8] Liu, M., Scordino, R., Geurtz, R., Navarrete, C., Ko, Y., Lim, M. (2014). A look at research on mobile learning in K-12 education from 2007 to the present. Journal of research on Technology in Education, 46(4): 325-372. https://doi.org/10.1080/1539 $\underline{1523.2014 .925681}$

[9] Shuler, C. (2009). Pockets of potential: Using mobile technologies to promote children's learning at sesame workshop. New York, NY: The Joan Ganz Cooney Center. https://doi. org/10.1080/03054985.2011.577940

[10] Erstad, O. (2012). The learning lives of digital youth — beyond the formal and informal. Oxford Review of Education, 38(1): 25-43.

[11] Li, X. (2018). Design and Application of Children's Entertainment Education Software in Preschool Education. International Journal of Emerging Technologies in Learning, 13(7).

[12] Amin, M.N., Kaprawi, N. (2019). Content Learning Indicator in Equivalence Checking between Skills Module and Academic Module for APEL Process. International Journal of Emerging Technologies in Learning (iJET), 14(20): 58-72. https://doi.org/10.3991/ijet.v14 $\underline{\mathrm{i} 20.11459}$

[13] Marcus, V.B., Atan, N.A., Talib, R., Latif, A.A., Yusof, S.M. (2019). Promoting Students' Generic Skills with the Integration of e-Service Learning Platform. International Journal of Emerging Technologies in Learning (iJET), 14(20): 4-17. https://doi.org/10.3991/ijet.v14 $\underline{\mathrm{i} 20.11455}$

[14] Radesky, J.S., Schumacher, J., Zuckerman, B. (2015). Mobile and interactive media use by young children: The good, the bad, and the unknown. Pediatrics, 135(1): 1-3. https://doi. org/10.1542/peds.2014-2251

[15] Norén Creutz, I., Wiklund, M. (2014). Learning Paradigms in Workplace ELearning Research. Knowledge Management and E-Learning, 6(3): 299-315.

[16] Martin, F., Ertzberger, J. (2013). Here and Now Mobile Learning: An Experimental Study on the Use of Mobile Technology. Computers and Education, 68: 76-85. https://doi.org/ 10.1016/j.compedu.2013.04.021

[17] Palalas, A. (2012). Design Guidelines for a Mobile-Enabled Language Learning System Supporting the Development of ESP Listening Skills. Unpublished PhD diss., Centre for Distance Education, Athabasca University.

[18] Levy, M. (2009). Technologies in Use for Second Language Learning. The Modern Language Journal, 93: 769-782. https://doi.org/10.1111/j.1540-4781.2009.00972.x

[19] Schoonenboom, J. (2012). The Use of Technology as One of the Possible Means of Performing Instructor Tasks: Putting Technology Acceptance in Context. Computers and Education, 59(4): 1309-1316. https://doi.org/10.1016/j.compedu.2012.06.009

[20] Viberg, O., Grönlund, Å. (2015). Understanding students' learning practices: challenges for design and integration of mobile technology into distance education. Learning, Media and Technology, 42(3): 357-377. https://doi.org/10.1080/17439884.2016.1088869

[21] Liamputtong, P. (2011). Focus Group Methodology: Principles and Practice. London: Sage.

[22] Tuttas, C.A. (2015). Lessons Learned Using Web Conference Technology for Online Focus Group Interviews. Qualitative Health Research, 25 (1): 122-133. https://doi.org/10. $\underline{1177 / 1049732314549602}$

[23] Halperin, R., Backhouse, J. (2007). Using Structuration Theory in IS Research: Operationalizing Key Constructs. In Proceedings of the 28th International Conference on Information Systems, Paper 127. Montreal, Canada.

[24] Oliver, M. (2015). From Openness to Permeability: Reframing Open Education in Terms of Positive Liberty in the Enactment of Academic Practices. Learning, Media and Technology, 40(3): 365-384. https://doi.org/10.1080/17439884.2015.1029940 
Paper-Mobile Application Development for Technology Enhanced Learning: An Applied Study...

[25] Vogel, D., Kennedy, D., Kwok, R.C.W. (2009). Does Using Mobile Devices Applications Lead to Learning? Journal of Interactive Learning Research, 20(4): 469-485.

[26] Lai, C., Gu, M. (2011). Self-Regulated Out-of-Class Language Learning with Technology. Computer Assisted Language Learning, 24(4): 317-335. https://doi.org/10.1080/0958822 1.2011 .568417

[27] Stockwell, G., Hubbard, P. (2013). Some Emerging Principles for Mobile-Assisted Language Learning. The International Research Foundation for English Language Education (TIRF).

\section{$7 \quad$ Author}

Nidal Al Said has PhD degree. He works as Assistant Professor at College of Mass Communication, Ajman University, Ajman, United Arab Emirates.

Article submitted 2019-11-29. Resubmitted 2020-01-12. Final acceptance 2020-01-13. Final version published as submitted by the authors. 